\title{
SHORT-DISTANCE PROGNOSIS OF SCHIZOPHRENIA
}

\author{
BY
}

\author{
E. GUTTMANN, W. MAYER-GROSS, AND E. T. O. SLATER
}

From the Research Unit of the Maudsley Hospital

(ReCEIVEd 22ND August, 1938)

To make an assessment of the value of the new methods of treatment of schizophrenia by hypoglycæmia or convulsions, it is necessary to have comparative material on the course of the disease without such treatment. The ideal method of obtaining such material would be by the provision of a control series of cases, selected at the same time and in the same way as a treatment series, and by the comparison of these two groups one with another. The obstacles in the way of any such investigation are, however, very considerable : it is, for instance, very difficult to refuse treatment to a suitable case for purely scientific reasons, especially if one has any strong belief in the value of treatment. The testing of a system of treatment by simultaneous controls can only be carried out at a time when no one has any great faith in the value of the treatment. In the case of the modern treatment of schizophrenia, this time is already past. It remains, therefore, to provide comparative figures on the course of the disease without active treatment from the data of previous years.

Most authors who have made prognostic studies of schizophrenia have been particularly interested in the final outcome, and have therefore followed up their cases for the longest possible period of time. In so far as the more immediate subsequent history is neglected, these studies are of little relevance to the problem that now faces us. For obvious reasons one wishes to know just now more of the course of the illness within the first few years of the onset, and the need of comparative material for this period has been emphasized by workers with the new methods of treatment. Judgment of the final effects of treatment will in any case have to be postponed for many years.

From recently published statistics it is difficult to obtain any satisfactory picture of the course of schizophrenia, since the material of the various authors differs in fundamental respects. For instance, the remission rate of mental hospital patients will necessarily be much lower than that of the early and acute cases admitted into observation wards or into the university clinics of the Continent. The material investigated is not sufficiently characterized merely by the diagnosis "schizophrenia" : its character from the prognostic point of view is largely determined by the administrative type of the hospital and the legal and social requirements and conditions governing admission. This has rarely been discussed by previous writers. 
Wootton and co-workers have followed up 104 schizophrenics admitted to Ewell Mental Hospital between 1928 and 1931. At the time of investigation (published 1935), 47 of these cases had been discharged, of whom 18 had made a total recovery ; one more was able to live in a sheltered environment outside hospital ; another had a minor relapse only ; and another nine cases had had to be re-admitted to a mental hospital. In other words, they found a recovery rate of less than 20 per cent. for an observation period of 2 to 5 years.

Among authors who have collected material with a special view to comparison with the results of insulin (or cardiazol) treatment, Dussik found similarly 20 per cent. of spontaneous recoveries. Faurbye states that of 72 patients whose illness was of comparatively recent onset and who had been admitted to the hospital at least one year previously, 40 were discharged from hospital, and of these 40, 30 had more or less recovered. He found therefore a crude recovery rate of 42 per cent. On the other hand, Ederle states that of 197 schizophrenics treated in the Tübingen clinic in 1935 only 3 to 4 per cent. left the clinic in a full remission. The length of treatment is not stated, and it seems likely that a number of patients left the clinic for a mental hospital, but subsequently recovered there.

Braatöy collected his material from a mental hospital, and followed up the cases for 5-7 years after their admission. Among the schizophrenics he found at the time of the inquiry 20 per cent. recovered and approximately another 10 per cent. improved. Horwitz and Kleiman's figures are not comparabie with ours, since the period of observation of recent cases is much shorter. Furthermore, they dealt only with the cases that had been discharged, and do not say how many cases were permanently invalided in hospital. Briner's results, which seem of all those in the literature the most comparable with ours, will be contrasted with our figures later on.

Considering the difficulty in finding an " average" material and having in mind a future comparison with treated cases, we have collected a material of schizophrenics selected (not by us) for particularly good prognostic outlook : for it would seem that if any treatment can offer better results than those obtained with this material, this method would be definitely justified; whereas an unfavourable comparison would have to be evaluated in the light of the selection of cases.

\section{The Material}

This investigation is based in the first instance on all the schizophrenics discharged from the Maudsley Hospital between 1st January, 1934, and 31st December, 1935, inclusive, and refers to their state on 1st January, 1938. In general, the Maudsley Hospital admits only those who prima facie have a favourable outlook. This constitutes a first selection of our material. Secondly, we ourselves excluded all cases of 46 years or older, all those cases whose illness antedated admission by more than 12 months, and all those cases in whom we had the slightest doubt of the diagnosis of schizophrenia.

For the purpose of this investigation, the first appearance of manifest psychological changes was regarded as the point of onset of the illness. Though 
it is difficult, as a rule, to determine this point with any accuracy, we were in a favourable position to do so, as several independent histories were generally available in the hospital notes. We feel satisfied that all cases with an insidious change in personality dating back longer than a year have been excluded. It was thought advisable to exclude all cases more than 45 years of age, as it seemed likely that patients older than this would not be taken for active treatment. Our diagnostic criteria were strictly applied. Cases were taken for follow-up only if all three investigators were agreed on the diagnosis. Our opinion was, however, based solely on the material available at the time of discharge. The seiection was carried out before the follow-up started, and no subsequent corrections of diagnosis have been made in the light of after-results. It seems only fair to say that we disagreed with the hospital clinicians as to the diagnosis (on grounds of insufficient certainty) only in a very small minority of cases.

\section{Method}

The patients were traced by correspondence, and information and records from all the hospitals and other institutions in which they had been since discharge from the Maudsley were obtained. In the case of those patients who were in a mental institution at the time of the inquiry, no further investigation was made. In the great majority of the other cases, however, further investigation was made by a social worker and by ourselves. The reports obtained from patients and relatives by letter were regarded as sufficient only where the information was unequivocal and the patients were inaccessible. In all other cases the social worker paid one or more visits to the home, and in cases of doubt the patients were induced to attend hospital to be seen by us. The numbers investigated in all these ways are given in Table 1 .

Table 1.-Collection of Material

\begin{tabular}{|c|c|c|c|c|c|c|}
\hline & & \multicolumn{2}{|c|}{ SEEN BY SOCIAL WORKER : } & \multicolumn{2}{|c|}{ SEEN BY DOCTOR : } & \multirow{2}{*}{$\begin{array}{l}\text { LETTER } \\
\text { ONLY }\end{array}$} \\
\hline & & PATIENT & RELATIVES & PATIENT & RELATIVES & \\
\hline $\begin{array}{ll}\text { MALE } & \\
\text { F.I. } & \cdots \\
\text { S.D. } & \cdots \\
\text { S.R. } & \cdots \\
\text { T.R. } & \cdots\end{array}$ & $\begin{array}{l}\cdots \\
\cdots \\
\cdots \\
\cdots\end{array}$ & $\begin{array}{l}2 \\
6 \\
2 \\
6\end{array}$ & $\begin{array}{l}4 \\
5 \\
5 \\
5\end{array}$ & $\begin{array}{l}1 \\
4 \\
2 \\
5\end{array}$ & $\begin{array}{l}1 \\
1 \\
2 \\
1\end{array}$ & $\begin{array}{l}4 \\
1 \\
2 \\
3\end{array}$ \\
\hline Total Male & . & 16 & 19 & 12 & 5 & 10 \\
\hline \multicolumn{7}{|c|}{ Untraced : 2} \\
\hline $\begin{array}{l}\text { FEMALE } \\
\text { F.I. } \quad \cdots \\
\text { S.D. } \\
\text { S.R. } \\
\text { T.R. }\end{array}$ & $\begin{array}{l}\ldots \\
\cdots \\
\cdots \\
\cdots\end{array}$ & $\begin{array}{r}2 \\
5 \\
8 \\
19\end{array}$ & $\begin{array}{r}1 \\
4 \\
9 \\
12\end{array}$ & $\begin{array}{l}5 \\
1 \\
1 \\
4\end{array}$ & $\begin{array}{l}2 \\
1 \\
1 \\
2\end{array}$ & $\begin{array}{l}5 \\
1 \\
2 \\
6\end{array}$ \\
\hline Total Female & & 34 & 26 & 11 & 6 & 14 \\
\hline \multicolumn{7}{|c|}{ Untraced : 2 . } \\
\hline $\begin{array}{l}\text { SUM TOTAL } \\
\text { M. and F. }\end{array}$ & $\ldots$ & 50 & 45 & 23 & 11 & 24 \\
\hline
\end{tabular}

Untraced : 4. 
As in all follow-up studies of this kind, it was not possible to make the investigation as complete as we desired. One may, however, say that the information obtained and the opinions formed by our well-trained social worker tallied with our own in every case where a check was possible. We wish to take this opportunity of thanking Miss M. A. Brown for her skilled and valuable assistance. Any errors in the classification of the state of recovery caused by insufficient information will tend to be in an optimistic direction - the degree of recovery will be overrated. The conclusions drawn will therefore be influenced, if at all, in the same direction as by our selection of optimal material.

\section{Classification of Results}

The classification of our results was carried out by the three writers conferring. The following standards, adopted from those suggested by M. Müller, were used :

T.R. = total recovery, freedom from symptoms and signs, return to previous social environment and to previous or to an equivalent occupation.

S.R. = social recovery, return to previous social environment and to previous or equivalent occupation, in spite of presence of minor signs and symptoms, such as irritability, shyness, shallowness of affective response, etc.

S.D. = social defect, presence of minor symptoms as above, incapacity to carry out work of previous level and failure to maintain self in the same degree of social adaptation.

F.I. =family invalid, presence of well-marked symptoms, incapacity to carry out any useful occupation, but manageable at home.

H.I. = hospital invalid, i.e. the inmates of mental hospitals, some continuously since discharge from the Maudsley, some relapsed after a temporary recovery.

D. $=$ dead.

$\mathrm{U} .=$ untraced.

\section{The Results}

The results of the investigation are given in Table 2. The most important fact to be drawn from this table is that (after an average period of observation slightly exceeding three years) 41 per cent. of the cases are in mental hospitals. Including family invalids, one may say that more than one half of the cases have deteriorated to a point where they must be regarded as invalids. On the other hand, over a third ( 34.5 per cent.) have made a recovery to a point where, from the purely social aspect, they are as good as they were before the illness, without any of the modern drastic therapeutic measures. The recoveries with social defect $(8 \cdot 3$ per cent.) form an intermediate group. They certainly cannot be spoken of as recovered, but they are not a burden on the community.

The significance of our material for comparison with the results of treatment is illustrated by the following example. Horányi-Hechst and Szatmári have 
recently published a paper in which they express their scepticism as to the value of insulin treatment. They treated 64 patients, and attained 47 per cent. of what we would call total and social recoveries. They regard this as exactly what one would expect in the light of previously published statistics from an untreated material. If, however, one considers that in their 64 cases there were nearly a third (21) chronic cases, and that their results are better than those found in the present optimal material of recent onset and favourable prognosis, the comparison is greatly to the advantage of the treated material.

\section{TABle 2.-Final Results}

\begin{tabular}{|c|c|c|c|c|c|c|c|c|}
\hline & & & M. & PER CENT. & F. & PER CENT. & тот. & PER CENT. \\
\hline \multirow[t]{2}{*}{$\begin{array}{l}\text { H.I. with free } \\
\text { H.I. without, } \\
\text { F.I. . . } \\
\text { S.D. . } \\
\text { S.R. . . } \\
\text { T.R. . . } \\
\text { D. . . } \\
\text { Untraceable }\end{array}$} & 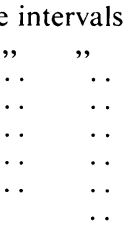 & $\begin{array}{l}\cdots \\
\cdots \\
\cdots \\
\cdots \\
\cdots \\
\cdots \\
\cdots \\
\cdots\end{array}$ & $\begin{array}{r}10 \\
24 \\
9 \\
8 \\
8 \\
13 \\
5 \\
2\end{array}$ & $\begin{array}{r}12 \cdot 7 \\
30 \cdot 4 \\
11 \cdot 4 \\
10 \cdot 1 \\
10 \cdot 1 \\
16 \cdot 5 \\
6 \cdot 3 \\
2 \cdot 5\end{array}$ & $\begin{array}{r}15 \\
28 \\
9 \\
7 \\
17 \\
29 \\
2 \\
2\end{array}$ & $\begin{array}{r}13 \cdot 8 \\
25 \cdot 7 \\
8 \cdot 3 \\
6 \cdot 4 \\
15 \cdot 6 \\
26 \cdot 6 \\
1 \cdot 8 \\
1 \cdot 8\end{array}$ & $\begin{array}{r}25 \\
52 \\
18 \\
15 \\
25 \\
42 \\
7 \\
4\end{array}$ & $\begin{array}{r}13 \cdot 2 \\
28 \cdot 0 \\
9 \cdot 7 \\
8 \cdot 3 \\
13 \cdot 0 \\
21 \cdot 5 \\
4 \cdot 1 \\
2 \cdot 2\end{array}$ \\
\hline & & & 79 & $100 \cdot 0$ & 109 & $100 \cdot 0$ & 188 & $100 \cdot 0$ \\
\hline
\end{tabular}

A few observations should be made on our figures. In Figs. 1 and 2 the individual careers, in and out of hospital, are given of 101 of the female and 69 of the male patients, classified according to their final state. The patients omitted are those about whom sufficient information is not available to draw up accurate figures, i.e. those who died early, who were untraced, and a few others. From the figures a clear picture is obtainable of the variability of length of first and subsequent illnesses, of the frequency of relapses, and the

TABLE 3

\begin{tabular}{|c|c|c|c|c|c|c|c|c|}
\hline & & 1 & \multicolumn{2}{|c|}{$\begin{array}{l}\text { AVERAGE PERIOD } \\
\text { OF TREATMENT IN } \\
\text { MAUDSLEY HOSPITAL } \\
\text { (MONTHS) }\end{array}$} & \multicolumn{2}{|c|}{$\begin{array}{l}\text { AVERAGE PERIOD OF } \\
\text { HOSPITALIZATION } \\
\text { (MONTHS) }\end{array}$} & \multicolumn{2}{|c|}{$\begin{array}{l}\text { AVERAGE PERIOD OF } \\
\text { OBSERVATION } \\
\text { (MONTHS) }\end{array}$} \\
\hline & & & M. & $\mathrm{F}$. & M. & F. & M. & F. \\
\hline $\begin{array}{l}\text { T.R. } \\
\text { S.R. } \\
\text { S.D. } \\
\text { F.I. } \\
\text { H.I. } \\
\text { D. } \\
\text { Untraced }\end{array}$ & $\begin{array}{l}\ldots \\
\cdots \\
\cdots \\
\cdots \\
\cdots \\
\ldots \\
\cdots\end{array}$ & 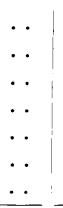 & $\begin{array}{l}4 \\
3 \\
5 \\
4 \\
4\end{array}$ & $\begin{array}{l}5 \\
5 \\
8 \\
4 \\
4\end{array}$ & $\begin{array}{r}5 \cdot 5 \\
5 \cdot 0 \\
11 \cdot 1 \\
11 \cdot 9 \\
35 \cdot 7 \\
5 \cdot 0 \\
5 \cdot 0 \\
\end{array}$ & $\begin{array}{r}6 \cdot 6 \\
6 \cdot 8 \\
6 \cdot 3 \\
9 \cdot 9 \\
34 \cdot 1 \\
8 \cdot 0 \\
3 \cdot 5 \\
\end{array}$ & $\begin{array}{r}40 \cdot 0 \\
33 \cdot 1 \\
43 \cdot 0 \\
42 \cdot 6 \\
39 \cdot 3 \\
5 \cdot 2 \\
11 \cdot 0 \\
\end{array}$ & $\begin{array}{r}37.9 \\
39 \cdot 4 \\
39.4 \\
36.4 \\
39.5 \\
15.5 \\
3.5 \\
\end{array}$ \\
\hline \multicolumn{2}{|c|}{$\begin{array}{l}\text { Average male } \\
\text { Average female }\end{array}$} & $\begin{array}{ll}\ldots & \\
\ldots & \\
\end{array}$ & & & $20 \cdot 7$ & $18 \cdot 2$ & $38 \cdot 5$ & $38 \cdot 7$ \\
\hline \multicolumn{2}{|c|}{ Total Average } & $\ldots$ & & & \multicolumn{2}{|c|}{$19 \cdot 2$} & \multicolumn{2}{|c|}{$38 \cdot 6$} \\
\hline
\end{tabular}


distribution of long and short illnesses and relapses between the cases of good and those of bad prognosis, and the different amount of hospitalization in the different groups (for which see also Table 3).

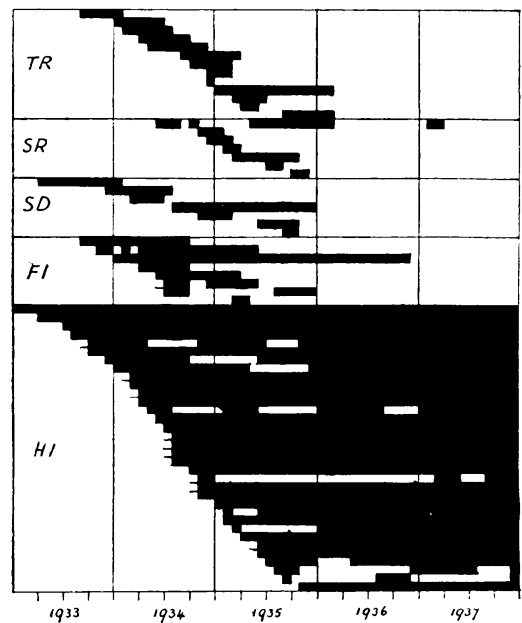

Fig. 1.-Males. Each horizontal line represents the career of a single patient. Black represents time spent in hospital.

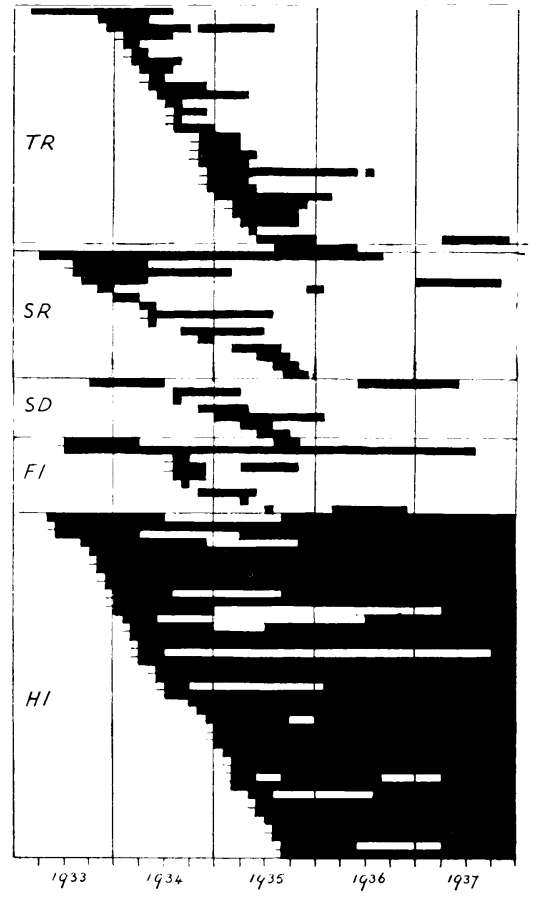

Fig. 2.-Females. Each horizontal line represents the career of a single patient. Black represents time spent in hospital.

TABLE 4

\begin{tabular}{|c|c|c|c|c|c|c|}
\hline \multirow[t]{2}{*}{$\begin{array}{l}\text { MONTHS AFTER } \\
\text { 1ST ADMISSION TO } \\
\text { HOSPITAL }\end{array}$} & \multicolumn{2}{|c|}{$\begin{array}{l}\text { STILL IN HOSPITAL, } \\
\text { PER CENT. }\end{array}$} & \multicolumn{2}{|c|}{$\begin{array}{c}\text { RECOVERED, I.E. OUT } \\
\text { OF HOSPITAL, FOR } \\
\text { IST OR SUBSEQUENT } \\
\text { TIME, } \\
\text { PER CENT. }\end{array}$} & \multicolumn{2}{|c|}{$\begin{array}{c}\text { RELAPSED, I.E. BACK } \\
\text { IN HOSPITAL, FOR } \\
\text { IST OR SUBSEQUENT } \\
\text { TIME, } \\
\text { PER CENT. }\end{array}$} \\
\hline & M. & F. & M. & F. & M. & $\mathrm{F}$. \\
\hline $\begin{array}{r}1 \\
2 \\
3 \\
4 \\
5 \\
6 \\
9 \\
12 \\
18 \\
24 \\
30 \\
36\end{array}$ & $\begin{array}{l}94 \\
82 \\
70 \\
67 \\
62 \\
53 \\
47 \\
42 \\
36 \\
36 \\
36 \\
35\end{array}$ & $\begin{array}{l}93 \\
85 \\
78 \\
69 \\
65 \\
58 \\
44 \\
36 \\
29 \\
28 \\
28 \\
28\end{array}$ & $\begin{array}{r}6 \\
18 \\
29 \\
30 \\
34 \\
43 \\
47 \\
48 \\
53 \\
53 \\
50 \\
49\end{array}$ & $\begin{array}{r}7 \\
15 \\
22 \\
31 \\
35 \\
41 \\
53 \\
60 \\
67 \\
64 \\
61 \\
60\end{array}$ & $\begin{array}{r}- \\
1 \\
3 \\
4 \\
4 \\
6 \\
10 \\
11 \\
11 \\
14 \\
16\end{array}$ & $\begin{array}{r}- \\
- \\
- \\
- \\
- \\
1 \\
3 \\
4 \\
4 \\
8 \\
11 \\
12\end{array}$ \\
\hline
\end{tabular}


Figs. 3 and 4 represent the curves of recovery of the male and female patients, and the essential data therein contained are given in Table 4. Both these figures and this table are based on the same reduced number of patients, about which full details are available. Both figures and table draw attention to the distinctly more favourable course of the psychosis in the female sex, as compared with the male. As will be seen from Table 5, the recovery rate, both from the first attack and from subsequent relapse, is greater in the female, and the relapse rate is lower. The same effect shows itself, of course, in Table 2.

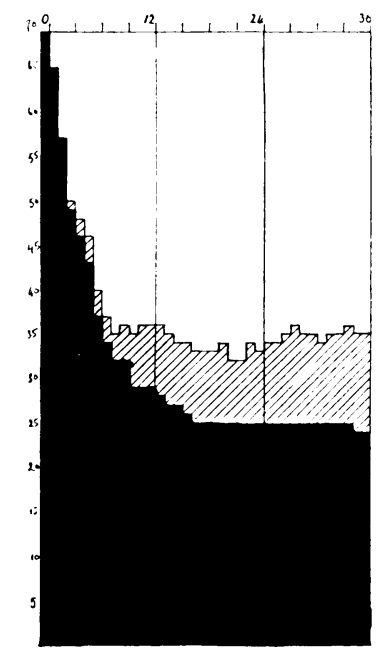

Fig. 3.-The curve of recovery in male patients. Every vertical line represents the number of patients recovered (white), relapsed (cross-hatched) or still ill (black) 1 to 36 months after the onset of the illness.

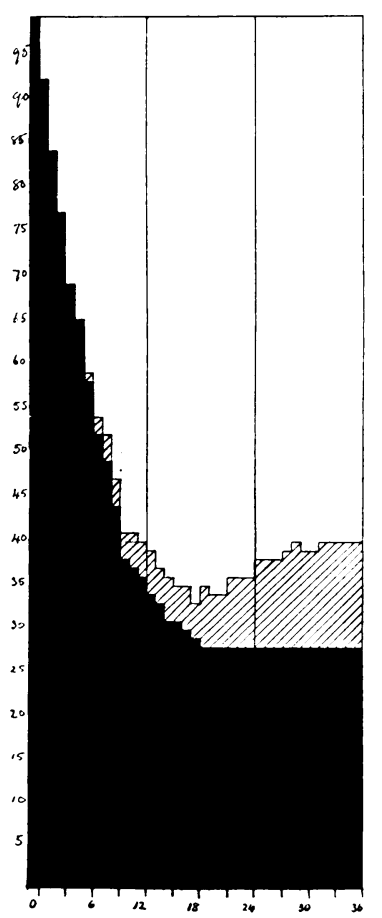

Fig. 4.-The curve of recovery in female patients. Every vertical line represents the number of patients recovered (white), relapsed (cross-hatched) or still ill (black) 1 to 36 months after the onset of the illness.

Of the males, 64.5 per cent. remained hospital or family invalids or recovered with defect ; only 26.4 per cent. made good social recoveries. Of the women, the corresponding percentages are 53.9 and 42.6 per cent.

\section{TABLE 5}

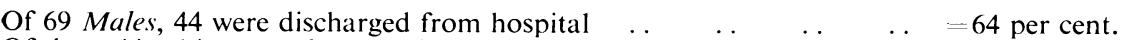

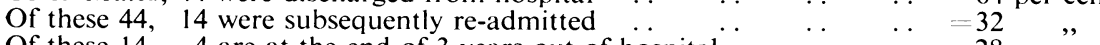

Of these 14, 4 are at the end of 3 years out of hospital $\quad \ldots \quad \ldots=28 \quad$,"

Of 98 Females, 73 were discharged from hospital $\quad \ldots \quad \ldots \quad \ldots=75 \quad$,

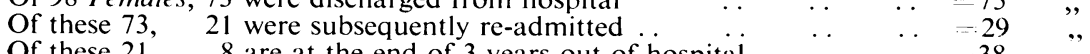

Of these $21, \quad 8$ are at the end of 3 years out of hospital $\quad \ldots \quad \ldots \quad=38 \quad$, 
Nothing certain can be said about the effect of age on the prognosis. Table 6 suggests that those whose illness begins at an age of 20 or less have a better prognosis than those who fall ill at a later age. The difference is, however, statistically not significant, though it might perhaps be regarded as suggestive $\left(\chi^{2}=4 \cdot 76\right.$, for which $\mathrm{P}=$ slightly less than $\left.0 \cdot 2\right)$. The same thing is seen in Table 7 : the hospital invalids are distinctly older than the average of patients, other groups distinctly younger ; and this is true of both sexes. Owing to the wide variation in age of the patients, expressed in the standard deviations, the results, though suggestive, cannot be significant. A much larger material might well disclose that age does have some bearing on the prognosis.

Table 6.-Prognosis AND Age at OnSET

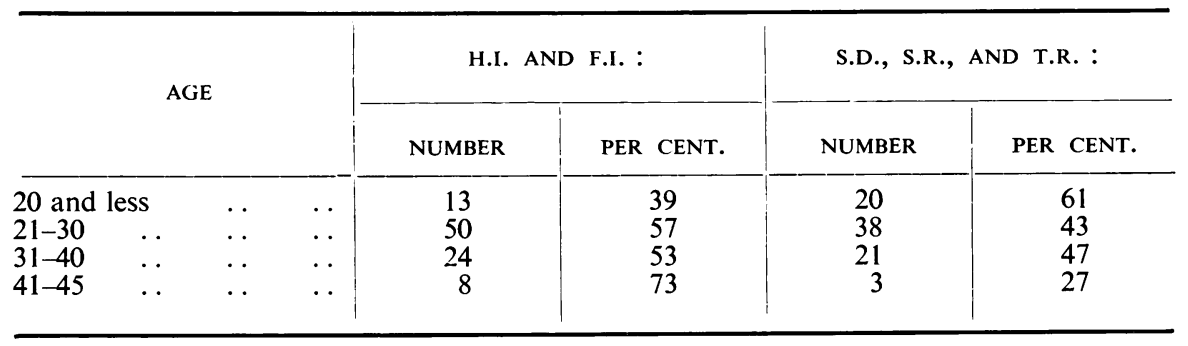

Table 7.-Average Ages

\begin{tabular}{|c|c|c|c|c|c|c|c|}
\hline & & M. & \pm & $\mathrm{F}$. & \pm & TOGETHER & \pm \\
\hline $\begin{array}{l}\text { H.I. } \\
\text { F.I. } \\
\text { S.D. } \\
\text { S.R. } \\
\text { T.R. } \\
\text { All }\end{array}$ & $\begin{array}{l}\cdots \\
\cdots \\
\cdots \\
\cdots \\
\cdots\end{array}$ & $\begin{array}{l}26 \cdot 8 \\
24 \cdot 6 \\
25 \cdot 5 \\
23 \cdot 0 \\
23 \cdot 6 \\
25 \cdot 6\end{array}$ & $\begin{array}{l}7 \cdot 0 \\
6 \cdot 7 \\
5 \cdot 5 \\
8 \cdot 0 \\
6 \cdot 1 \\
7 \cdot 0\end{array}$ & $\begin{array}{l}30 \cdot 0 \\
26 \cdot 2 \\
27 \cdot 7 \\
28 \cdot 3 \\
27 \cdot 2 \\
28 \cdot 6\end{array}$ & $\begin{array}{l}7 \cdot 8 \\
7 \cdot 6 \\
6 \cdot 2 \\
7 \cdot 6 \\
7 \cdot 5 \\
7 \cdot 8\end{array}$ & $\begin{array}{l}28 \cdot 6 \\
25 \cdot 4 \\
26 \cdot 5 \\
26 \cdot 6 \\
26 \cdot 1 \\
27 \cdot 4\end{array}$ & $\begin{array}{l}7 \cdot 3 \\
7 \cdot 2 \\
6 \cdot 1 \\
8 \cdot 1 \\
7 \cdot 2 \\
7 \cdot 4\end{array}$ \\
\hline
\end{tabular}

But one other point is of interest. Of the 44 men who were discharged from hospital, one married and had three children. Of the 73 women, 9 married after discharge, and 12 children were born. The post-diagnosis fertility of schizophrenics does not seem, therefore, to be very great.

\section{Discussion}

Briner's results are compared with ours in Table 8, and it will be seen that they are on the whole more favourable, in spite of the much heavier mortality rate. Both his and our material are alike in containing only schizophrenics with an illness of less than a year's duration. The length of time which Briner's cases and ours have been observed also corresponds, since his cases were those in hospital April, 1933-July, 1936. The difference in the results may be in part due to the different way in which Briner arranges them-he has, for instance, two categories of social remission where we have only one. A more important difference lies probably in the nature of the material ; Briner has a large number (23 per cent. of the total material) of " agitated catatonics." These provided 
about their due proportion (41 per cent.) of total and social remissions, but less than an average number of family and hospital invalids, and more than half his total number of deaths. This type of hyperacute case can be accommodated at the Maudsley, but only in limited numbers. We have not yet undertaken, as is projected, a closer clinical analysis of our cases ; but we anticipate that the percentage of disturbed and excited catatonics in our material will be substantially smaller than in Briner's. A third reason for the differences obtained may be the effect of treatment. Briner has made extensive use of continuous narcosis and also of a method of "Frühentlassung," by which patients are discharged from hospital at the earliest possible moment, often before full recovery is obtained, as a means of avoiding that stereotyping of symptoms which one often sees, or thinks one sees, in patients for long immured in a mental hospital. Briner states that of 33 cases where "Frühentlassung" was employed, 27 showed a good result. The actual effect of early discharge on his results is, however, not to be measured by this table.

TABLE 8

\begin{tabular}{|c|c|c|c|c|c|c|c|}
\hline & & & \multicolumn{2}{|c|}{ BRINER : } & \multicolumn{3}{|c|}{ MAUDSLEY MATERIAL : } \\
\hline & & & NUMBER & PER CENT. & NUMBER & PER & CENT. \\
\hline $\begin{array}{l}\text { H.I. and F.I. } \\
\text { S.D. } \\
\text { T.R. and S.R. } \\
\text { D. } \quad \text {. } \\
\text { U. } \quad .\end{array}$ & $\begin{array}{l}\ldots \\
\cdots \\
\cdots \\
\cdots \\
\cdots\end{array}$ & $\begin{array}{l}\cdots \\
\cdots \\
\cdots \\
\cdots\end{array}$ & $\begin{array}{r}82 \\
15 \\
111 \\
37 \\
22\end{array}$ & $\begin{array}{r}31 \\
6 \\
41 \\
14 \\
8\end{array}$ & $\begin{array}{r}95 \\
15 \\
67 \\
7 \\
4\end{array}$ & & $\begin{array}{r}51 \\
8 \\
35 \\
4 \\
2\end{array}$ \\
\hline Total & .. & . & 267 & 100 & 188 & & 100 \\
\hline
\end{tabular}

TABLE 9.-BRiner's MATERIAL

\begin{tabular}{|c|c|c|c|c|c|}
\hline & & \multicolumn{2}{|c|}{$\begin{array}{c}\text { TREATED BY } \\
\text { CONTINUOUS NARCOSIS : }\end{array}$} & \multicolumn{2}{|c|}{$\begin{array}{l}\text { NOT SO } \\
\text { TREATED : }\end{array}$} \\
\hline & & NUMBER & PER CENT. & NUMBER & PER CENT. \\
\hline \multirow[t]{2}{*}{$\begin{array}{l}\text { T.R., S.R. } \\
\text { S.R.2, S.D., F.I. } \\
\text { H.I., D. . }\end{array}$} & $\begin{array}{l}\ldots \\
\ldots \\
\ldots\end{array}$ & $\begin{array}{l}19 \\
12 \\
13\end{array}$ & $\begin{array}{l}43 \cdot 2 \\
27 \cdot 3 \\
29 \cdot 5\end{array}$ & $\begin{array}{l}53 \\
60 \\
88\end{array}$ & $\begin{array}{l}26 \cdot 4 \\
29 \cdot 4 \\
43 \cdot 7\end{array}$ \\
\hline & & 44 & $100 \cdot 0$ & 201 & $100 \cdot 0$ \\
\hline
\end{tabular}

Briner also claims very valuable results from continuous narcosis, a method of treatment that was not at all extensively applied at the Maudsley in the years 1934 and 1935. Briner's tables bearing on this point are unfortunately not intelligible to us. From the original data provided we have drawn up Table 9, in which Briner's two degrees of social recovery are separated from one another. This arrangement is statistically the most favourable possible, and shows an 
increase of 64 per cent. in the best class of recoveries obtained with continuous narcosis on the percentage obtained without such treatment. Though the difference is considerable the numbers are too small to have convincing statistical significance $\left(\chi^{2}=5 \cdot 273, \mathrm{P}>0 \cdot 05\right)$. We think, however, that the factor of treatment by this method also contributes to the difference between Briner's results and ours. It will be interesting to see whether, in the course of time, insulin and cardiazol treatment will be capable of producing a substantial improvement on either series of results.

\section{Summary}

1. A prognostically favourable group of 188 schizophrenics has been followed over an average period of over three years.

2. Of this group 41 per cent. are now in mental hospitals and over 50 per cent. are invalids at home or in hospital. Over one third have made total or social recoveries.

3. The course of the illness over the whole of the three years is illustrated by diagrams and the recovery and relapse rates during that period are given in tables. The influence of sex and age at onset are studied, and it is found that the prognosis in females is generally better than in males.

4. The results obtained are compared with those of other authors, and the possible influence of treatment by continuous narcosis is discussed.

We wish to thank Professor E. Mapother for permission to use the clinical material and the facilities of the Maudsley Hospital, and for his interest in our work. Two of the writers (M.-G., E. G.) have worked with the support of the Rockefeller Foundation.

\section{REFERENCES}

Braatöy, T. (1936). Acta psychiat. Kbh., 11, 63.

Briner, O. (1938). Z. ges. Neurol. Psychiat., 162, 582.

Dussik, K. T. (1937). Schweiz. Arch. Neurol. Psychiat., 39, 182.

Ederle, W. (1937). Münch. med. Wschr., 84, 1,811.

Faurbye, A. (1937). Nord. med. Tidskr., 13, 206. (Abstr. Brit. Med. J.)

Horányi-Hechst, B., and Szatmâri, A. (1938). Mschr. Psychiat. Neurol., 98, 101.

Horwitz, W. A., and Kleiman, C. (1936). Psychiat. Quart., 10, 72.

Müller, M., Schweiz. Arch. Neurol. Psychiat. (1937), 39, 9.

Wootton, L. H., Armstrong, R. W., and Lilly, D. (1935). J. ment. Sci., 81, 168.

\section{ADDENDUM}

Since this paper has been concluded further statistics have appeared which, however, differ so materially that discussion would exceed the bounds of a footnote. The reader is referred to various articles in the Psychiatric Quarterly for July, 1938 (Vol. 12, No. 3), and further to the Board of Control Report on Cardiazol Treatment and on the Present Application of Hypoglycæmic Shock Treatment in Schizophrenia by W. Rees Thomas and Isabel G. H. Wilson, London, 1938. 